\title{
Supernumerary Renal Arteries and Their Embryological and Clinical Correlation: A Cadaveric Study from North India
}

\author{
Virendra Budhiraja, ${ }^{1}$ Rakhi Rastogi, ${ }^{1}$ Vaibhav Anjankar, ${ }^{1}$ \\ C. S. Ramesh Babu, ${ }^{2}$ and Prabhat Goel ${ }^{3}$ \\ ${ }^{1}$ Department of Anatomy, L. N. Medical College and Research Center, Bhopal, India \\ ${ }^{2}$ Department of Anatomy, Muzaffarnagar Medical College, Muzaffarnagar, India \\ ${ }^{3}$ Department of Anatomy, Subharti Medical College, Meerut, India
}

Correspondence should be addressed to Virendra Budhiraja; virendrabudhiraja1970@gmail.com

Received 27 December 2012; Accepted 17 January 2013

Academic Editors: A. Capehart and M. Guvencer

Copyright (C) 2013 Virendra Budhiraja et al. This is an open access article distributed under the Creative Commons Attribution License, which permits unrestricted use, distribution, and reproduction in any medium, provided the original work is properly cited.

Background. Classically, each kidney is supplied by a single renal artery originating from abdominal aorta. The present study aimed at its variations and their embryological and clinical correlation. Material and Methods. The formalin-fixed thirty-seven cadavers from north India constituted the material for the study. During routine abdominal dissection conducted for medical undergraduates at the department of anatomy, the kidneys along with their arteries were explored and the morphological variations of renal arteries were noted. Results. We observed supernumerary renal arteries in 23/37 (62.2\%) cases (48.6\% of aortic origin and $13.5 \%$ of renal origin) on the right side and $21 / 37$ (56.8\%) cases (45.9\% of aortic origin and $10.8 \%$ of renal origin) on the left side. Supernumerary renal arteries entered the kidney through hilum, superior pole, and inferior pole. Conclusion. Awareness of variations of renal artery is necessary for surgical management during renal transplantation, repair of abdominal aorta aneurysm, and urological procedures and for angiographic interventions.

\section{Introduction}

Classically, the description of a single renal artery arising from abdominal aorta that supplies the respective kidney $[1,2]$ occurs in less than $25 \%$ of cases $[3,4]$. Common variations of renal artery are its variable number and unusual branching pattern [5-9]. Variations in renal arteries have been called aberrant, supplementary, and accessory, among other terms. We used the term supernumerary and analyze it in accordance with Merklin classification [10]. We believe that prior knowledge of these possible variations of renal arteries may help the surgeon in planning renal transplantation, repair of abdominal aorta aneurysm, urological procedures, and also for angiographic interventions [11-13].

\section{Materials and Methods}

The formalin-fixed thirty-seven cadavers constituted the material for the study. During routine abdominal dissection conducted for medical undergraduates at the department of anatomy, the kidneys along with their arteries were explored and the morphological variations of renal arteries were noted. During the course of dissection various abdominal viscera were removed and preserved as specimens for teaching purposes. We studied the origin of supernumerary renal arteries in accordance to the nomenclature of Merklin and Michels [10]:

(1) supernumerary renal arteries originating from the aorta;

(2) supernumerary renal arteries originating from main renal arteries;

(3) supernumerary renal arteries that can come from other sources.

\section{Results}

Supernumerary renal arteries were present in 23/37 (62.2\%) cases $(48.6 \%$ of aortic origin and $13.5 \%$ of renal origin) on 


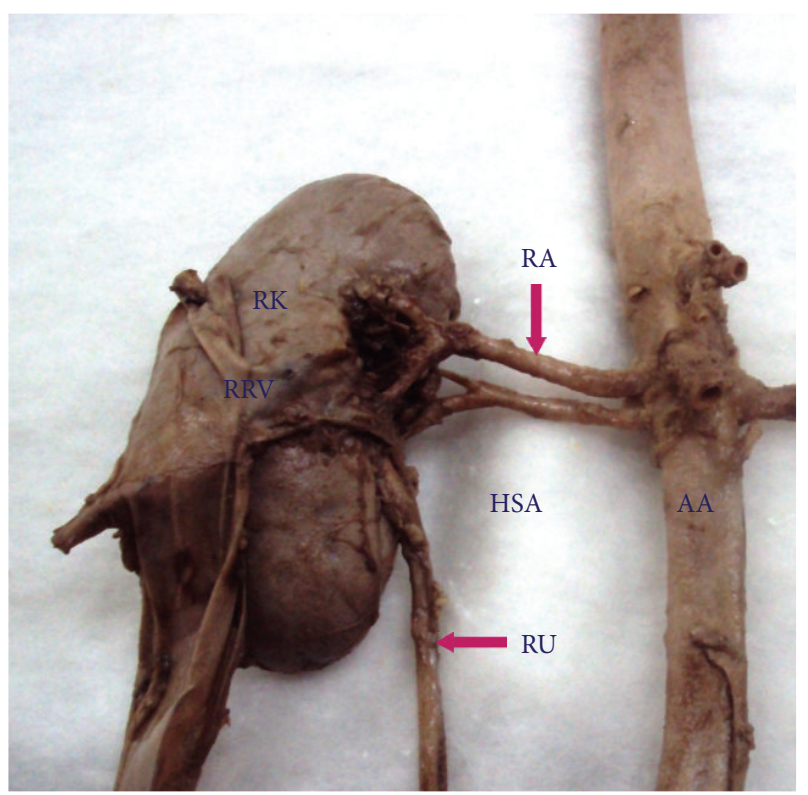

FIGURE 1: Right kidney showing hilar supernumerary renal artery originating from abdominal aorta. AA: abdominal aorta, RA: renal artery, HSA: hilar supernumerary renal artery, RK: right kidney, RU: right ureter, RRV: reflected renal vein.

the right side and $21 / 37$ (56.8\%) cases (45.9\% of aortic origin and $10.8 \%$ of renal origin) on the left side. The supernumerary renal arteries entered the kidney through hilum as hilar supernumerary renal artery (Figures 1, 2, and 5), through upper pole as upper polar supernumerary renal artery (Figures 3 and 4), and through lower pole as lower polar supernumerary renal artery (Figures 3 and 5). The finding with respect to origin, side, and mode of penetration to kidney is represented in Table 1 . We did not find any case where supernumerary renal artery was originating from other source like common iliac, testicular, ovarian, suprarenal, and so forth.

\section{Discussion}

The various types of (accessory, additional, supplementary, and aberrant) renal arteries, their positions, method of entry to the kidney, and segmentation were studied extensively by a number of authors $[14,15]$ but the generally accepted and precise terminology for these arteries has not been unified by the majority of authors [16]. As these arteries occupy a certain vascular area within the kidney and there is no anastomosis, either with the branches of the main or with branches of segmental renal arteries, we preferred the terminology supernumerary for these arteries and classified them in accordance with Merklin and Michels [10]. Merklin and Michels [10] classified these supernumerary renal arteries depending upon origin as supernumerary renal arteries originating from aorta, supernumerary renal arteries originating from the main renal artery, and supernumerary renal arteries originating from other arterial sources, but in their study none of the hilar supernumerary renal artery took origin from renal artery. Talovic et al. [17] reported that in $30.76 \%$ cases supernumerary renal arteries originated from aorta

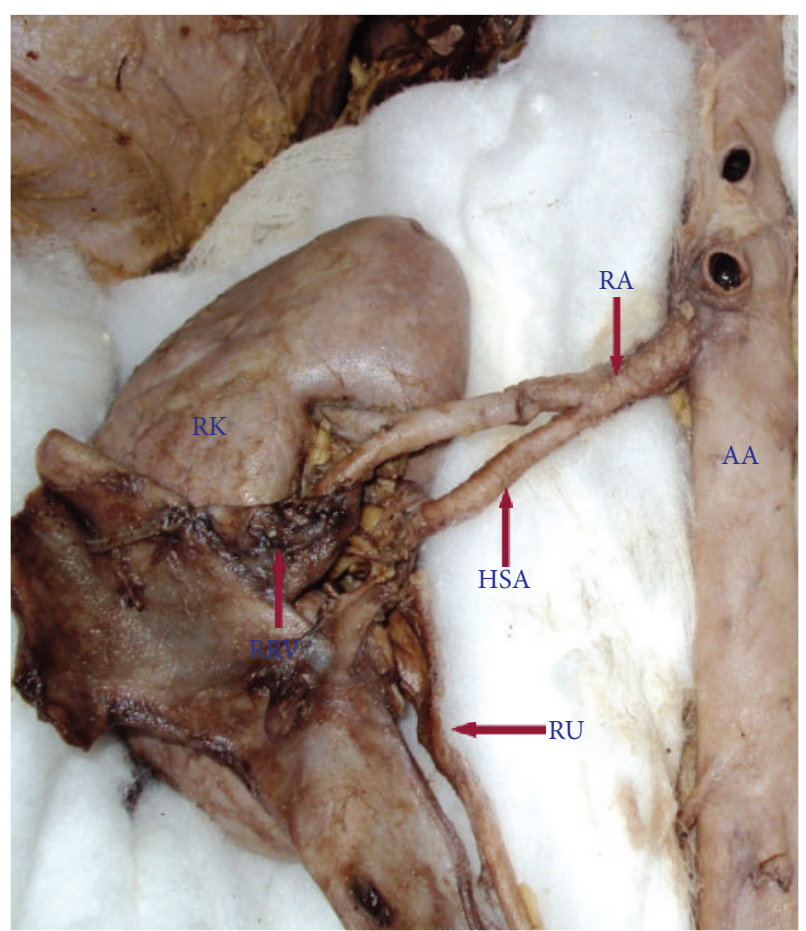

FIGURE 2: Right kidney showing hilar supernumerary renal artery originating from renal artery. AA: abdominal aorta, RA: renal artery, HSA: hilar supernumerary renal artery, RK: right kidney, RU: right ureter, RRV: reflected renal vein.

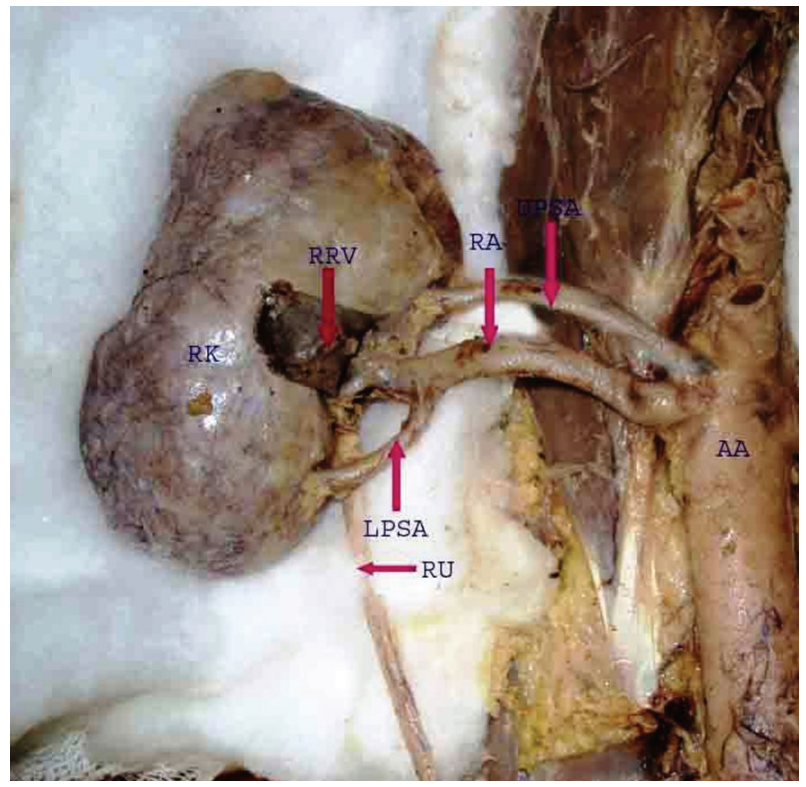

FIGURE 3: Right kidney showing upper polar supernumerary renal artery originating from abdominal aorta and lower polar supernumerary renal artery originating from renal artery. AA: abdominal aorta, RA: renal artery, UPSA: upper polar supernumerary renal artery, LPSA: lower polar supernumerary renal artery, RK: right kidney, RU: right ureter, RRV: reflected renal vein. 
TABLE 1: Number, percentage, and types of supernumerary renal arteries.

\begin{tabular}{lccc}
\hline Number of renal artery & Right kidney (\%) & Left kidney (\%) & Total (\%) \\
\hline One artery & $14 / 37(37.8 \%)$ & $16 / 37(43.2 \%)$ & $30 / 74(40.5 \%)$ \\
Supernumerary renal artery & $23 / 37(62.2 \%)$ & $21 / 37(56.8 \%)$ & $44 / 74(59.5 \%)$ \\
(A) Aorta origin & $\mathbf{1 8 / 3 7 ( 4 8 . 6 \% )}$ & $\mathbf{1 7 / 3 7}(45.9 \%)$ & $\mathbf{3 5 / 7 4}(47.3 \%)$ \\
HSA & $09 / 37(24.3 \%)$ & $07 / 37(18.9 \%)$ & $16 / 74(21.6 \%)$ \\
UPSA & $06 / 37(16.2 \%)$ & $05 / 37(13.5 \%)$ & $11 / 74(14.9 \%)$ \\
LPSA & $03 / 37(8.1 \%)$ & $05 / 37(13.5 \%)$ & $08 / 74(10.8 \%)$ \\
(B) Renal origi & $\mathbf{0 5 / 3 7}(13.5 \%)$ & $\mathbf{0 4 / 3 7}(10.8 \%)$ & $\mathbf{0 9 / 7 4}(12.2 \%)$ \\
HSA & $03 / 37(8.1 \%)$ & $03 / 37(8.1 \%)$ & $06 / 74(8.1 \%)$ \\
UPSA & $01 / 37(2.7 \%)$ & $01 / 37(2.7 \%)$ & $02 / 74(2.7 \%)$ \\
LPSA & $01 / 37(2.7 \%)$ & $0 / 37(0 \%)$ & $01 / 74(1.4 \%)$ \\
\hline
\end{tabular}

HSA: hilar supernumerary renal artery, UPSA: upper polar supernumerary renal artery, LPSA: lower polar supernumerary renal artery.

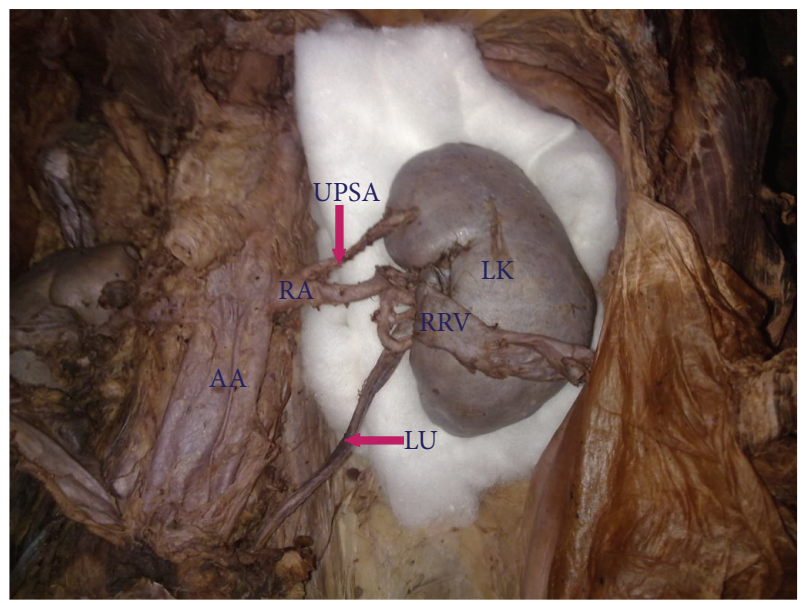

FIGURE 4: Left kidney showing upper polar supernumerary renal artery originating from renal artery. AA: abdominal aorta, RA: renal artery, UPSA: upper polar supernumerary renal artery, LK: left kidney, LU: left ureter, RRV: reflected renal vein.

and in $12.82 \%$ originated from renal arteries. In the present study the supernumerary arteries originated from abdominal aorta in $47.3 \%$ cases and from the main renal artery in $12.2 \%$ cases. We also observed hilar supernumerary renal arteries originating from renal artery in $8.1 \%$ cases.

Embryological explanation of these variations has been presented and discussed by Felix [18]. In an $18 \mathrm{~mm}$ fetus, the developing mesonephros, metanephros, suprarenal glands, and gonads are supplied by nine pairs of lateral mesonephric arteries arising from the dorsal aorta. Felix divided these arteries into three groups as follows: the 1st and 2nd arteries as the cranial, the 3 rd to 5 th arteries as the middle, and the 6 th to 9 th arteries as the caudal group. The middle group gives rise to the renal arteries. Persistence of more than one artery of the middle group results in multiple renal arteries [18]. Thus, the multiple renal arteries in our study are a result of persisting lateral mesonephric arteries from the middle group.

Clinically, the supernumerary renal arteries are very important. Upper polar and lower polar supernumerary renal arteries originating from renal arteries, directed towards superior or inferior pole, have vertical trajectory in comparison to supernumerary renal arteries taking origin from aorta. Vertical trajectory of these arteries can lead to polar infarction

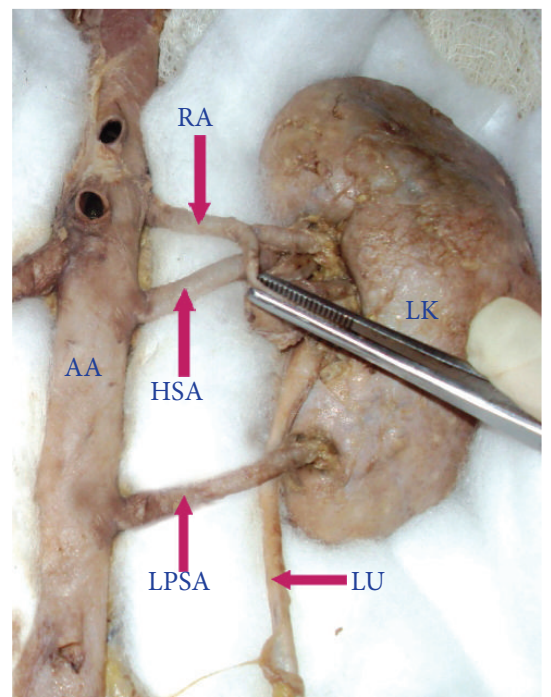

FIGURE 5: Left kidney showing hilar supernumerary renal artery and lower polar supernumerary renal artery originating from abdominal aorta. AA: abdominal aorta, RA: renal artery, HSA: hilar supernumerary renal artery, LPSA: lower polar supernumerary renal artery, LK: left kidney, LU: left ureter.

[19] and they can also be injured during mobilization and other surgical procedures [9]. Lower polar supernumerary renal arteries of aortic or renal origin can be a cause of ureteropelvic junction obstruction [20].

The anatomical knowledge of supernumerary renal arteries is essential before performing any transplantation surgeries where microvascular techniques are employed to reconstruct the renal arteries [21]. One has to keep in mind that transplanting a kidney with accessory renal arteries has several theoretical disadvantages: acute tubular necrosis and rejection episodes and decreased graft function [9].

We believe that awareness of variations is necessary for surgical management during renal transplantation, repair of abdominal aorta aneurysm, and urological procedures and for angiographic interventions.

\section{Conflict of Interests}

The authors declare that they have no conflict of interests. 


\section{References}

[1] J. P. Beregi, B. Mauroy, S. Willoteaux, C. Mounier-Vehier, M. Rémy-Jardin, and J. P. Francke, "Anatomic variation in the origin of the main renal arteries: spiral CTA evaluation," European Journal of Radiology, vol. 9, no. 7, pp. 1330-1334, 1999.

[2] U. Özkan, L. Oǧuzkurt, F. Tercan, O. Kizilkiliç, Z. Koç, and N. Koca, "Renal artery origins and variations: angiographic evaluation of 855 consecutive patients," Diagnostic and Interventional Radiology, vol. 12, no. 4, pp. 183-186, 2006.

[3] O. A. Awojobi, O. A. Ogunbiyi, and E. O. Nkposong, "Unusual relationship of multiple renal arteries," Urology, vol. 21, no. 2, pp. 205-206, 1983.

[4] A. E. Çiçekcibaşi, T. Ziylan, A. Salbacak, M. Şeker, M. Büyükmumcu, and I. Tuncer, "An investigation of the origin, location and variations of the renal arteries in human fetuses and their clinical relevance," Annals of Anatomy, vol. 187, no. 4, pp. 421427, 2005.

[5] P. Dhar and K. Lal, "Main and accessory renal arteries-a morphological study," Italian Journal of Anatomy and Embryology, vol. 110, no. 2, pp. 101-110, 2005.

[6] M. C. Rusu, "Human bilateral doubled renal and testicular arteries with a left testicular arterial arch around the left renal vein," Romanian Journal of Morphology and Embryology, vol. 47, no. 2, pp. 197-200, 2006.

[7] M. M. Shoja, R. S. Tubbs, A. Shakeri et al., "Peri-hilar branching patterns and morphologies of the renal artery: a review and anatomical study," Surgical and Radiologic Anatomy, vol. 30, no. 5, pp. 375-382, 2008.

[8] N. Krishnasamy, M. Rao, S. N. Somayaji, S. Koshy, and V. Rodrigues, "An unusual case of unilateral additional right renal artery and vein," International Journal of Anatomical Variations, vol. 3, pp. 9-11, 2010.

[9] F. J. B. Sampaio and M. A. R. F. Passos, "Renal arteries: anatomic study for surgical and radiological practice," Surgical and Radiologic Anatomy, vol. 14, no. 2, pp. 113-117, 1992.

[10] R. J. Merklin and N. A. Michels, "The variant renal and suprarenal blood supply with data on the inferior phrenic, ureteral and gonadal arteries: a statistical analysis based on 185 dissections and review of the literature," The Journal of the International College of Surgeons, vol. 29, no. 1, pp. 41-76, 1958.

[11] O. Olsson and M. Wholey, "Vascular abnormalities in gross anomalies of kidneys," Acta Radiologica, vol. 2, pp. 420-432, 1964.

[12] H. Nathan and I. Glezer, "Right and left accessory renal arteries arising from a common trunk associated with unrotated kidneys," Journal of Urology, vol. 132, no. 1, pp. 7-9, 1984.

[13] K. S. Satyapal, A. A. Haffejee, B. Singh, L. Ramsaroop, J. V. Robbs, and J. M. Kalideen, "Additional renal arteries: incidence and morphometry," Surgical and Radiologic Anatomy, vol. 23, no. 1, pp. 33-38, 2001.

[14] B. J. Anson, G. A. Richardson, and W. L. Minear, "Variations in the number and arrangements of the renal blood vessels, a study of the blood supply of four hundred kidneys," Journal of Urology, vol. 36, pp. 211-219, 1936.

[15] D. Sykes, "The arterial supply of the human kidney with special reference to accessory renal arteries," The British Journal of Surgery, vol. 50, pp. 368-374, 1963.

[16] G. Singh, Y. K. Ng, and B. H. Bay, "Bilateral accessory renal arteries associated with some anomalies of the ovarian arteries: a case study," Clinical Anatomy, vol. 11, no. 6, pp. 417-420, 1998.
[17] E. Talovic, A. Kulenovic, A. Voljevica, and E. Kapur, "Review of supernumerary renal arteries by dissection method," Acta Medica Academica, vol. 36, pp. 59-69, 2007.

[18] W. Felix, "Mesonephric arteries (aa. mesonephrica)," in Manual of Human Embryology, F. Keibel and F. P. Mall, Eds., vol. 22, pp. 820-825, Lippincott, Philadelphia, Pa, USA, 1912.

[19] R. W. Beyer and P. O. Daily, "Renal Artery Dissection Associated with Gz Acceleration," Aviation Space and Environmental Medicine, vol. 75, no. 3, pp. 284-287, 2004.

[20] M. M. Shoja, R. S. Tubbs, A. Shakeri, M. R. Ardalan, B. RahimiArdabili, and K. Ghabili, "Asymptomatic bilateral ureteropelvic junction obstruction due to supernumerary renal arteries," Saudi Journal of Kidney Disease and Transplantation, vol. 19, no. 5, pp. 806-808, 2008.

[21] G. E. Brannen, W. H. Bush, and R. J. Correa, "Microvascular management of multiple renal arteries in transplantation," Journal of Urology, vol. 128, no. 1, pp. 112-115, 1982. 

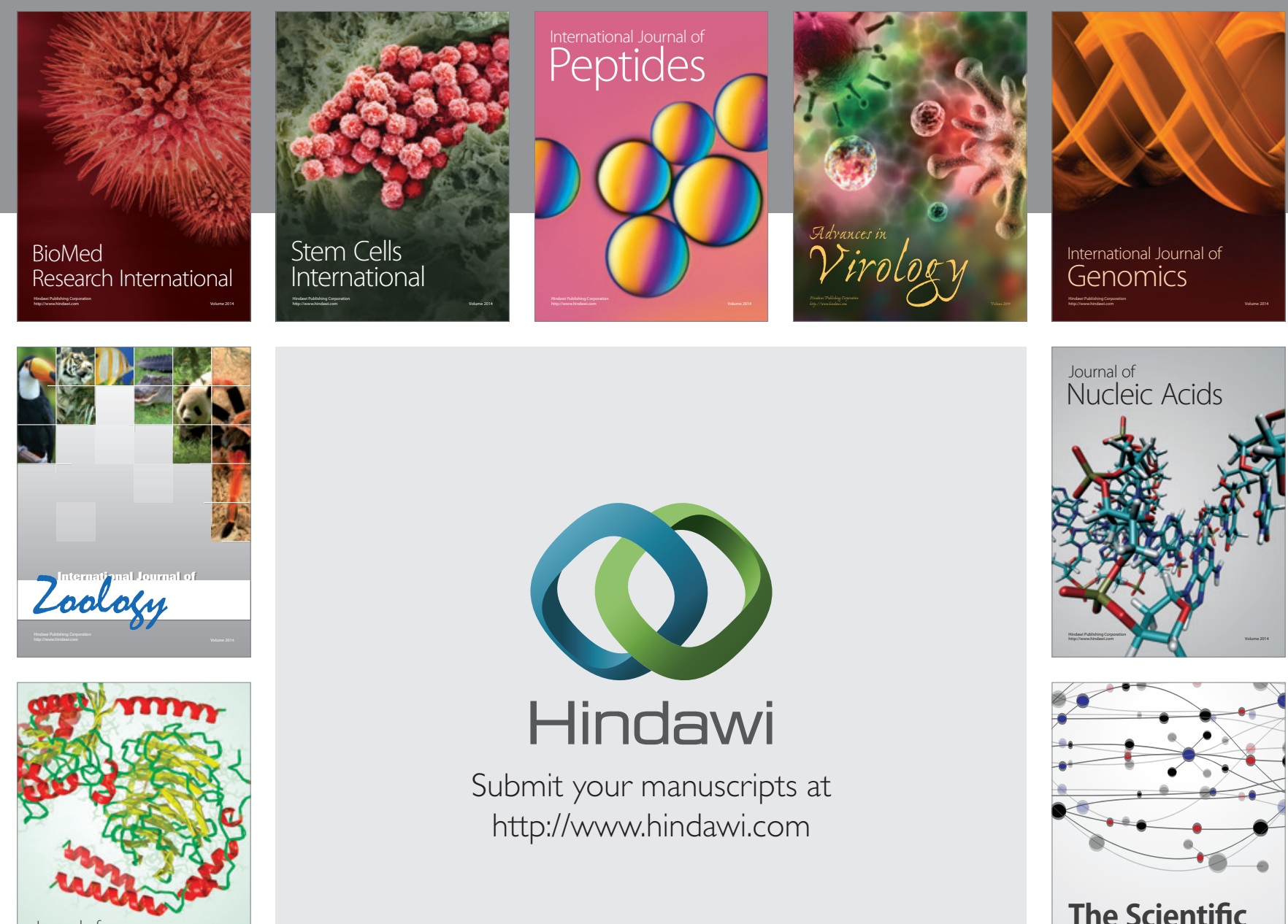

Submit your manuscripts at

http://www.hindawi.com

Journal of
Signal Transduction
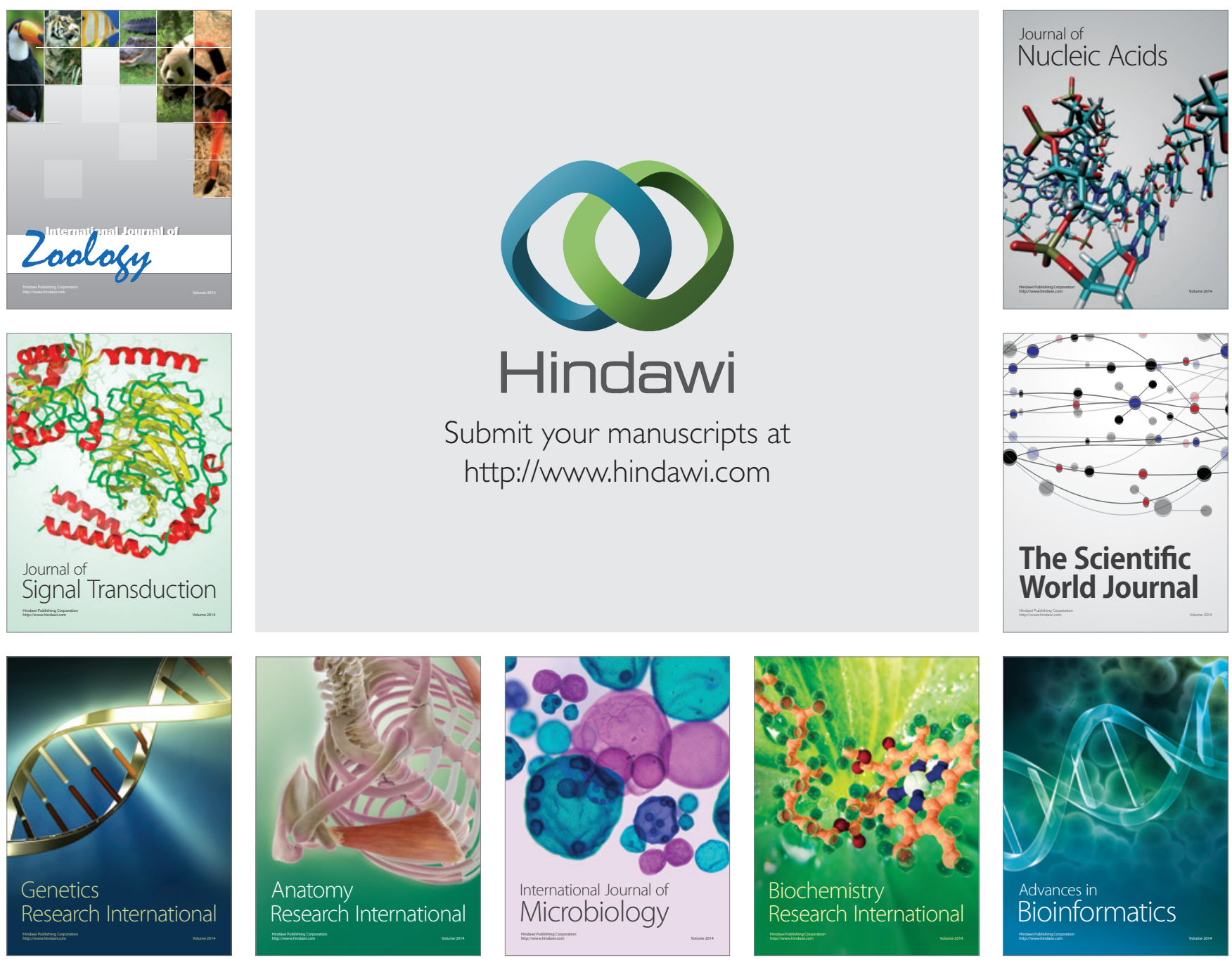

The Scientific World Journal
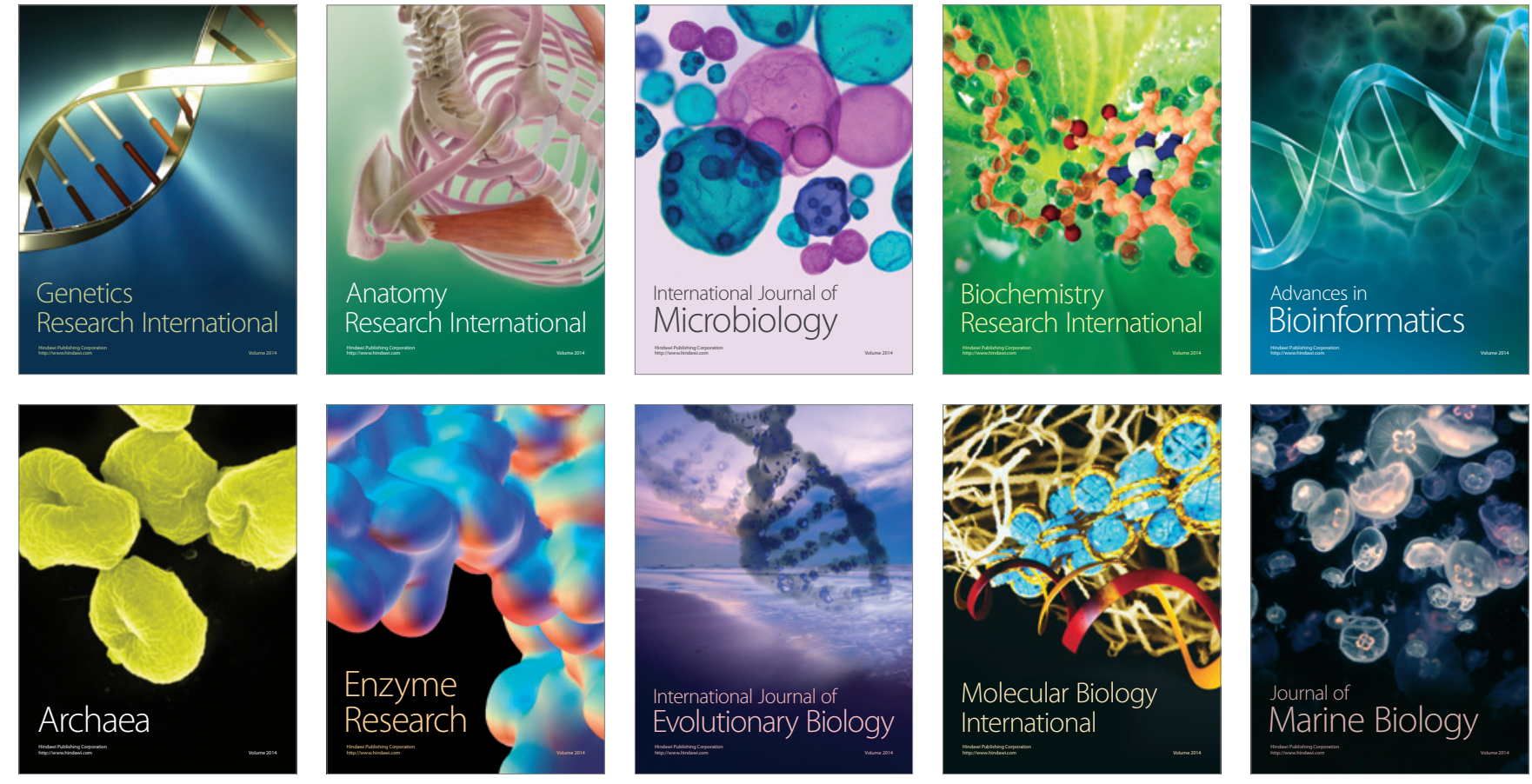